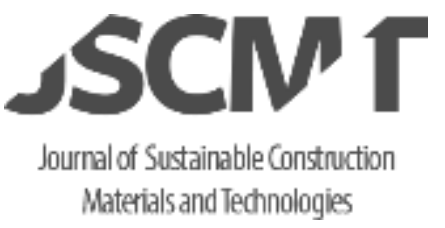

J Sustain. Construct. Mater. Technol. 3(3) (2018) 242-248 \begin{tabular}{c}
\hline \hline Journal of Sustainable \\
Construction Materials \\
and Technologies
\end{tabular}

www.eds.yildiz.edu.tr/jscmt

\title{
Investigating the Effects of Straw \& Rice Husk on the Compressive Strength \& Tensile Strength of Adobe Brick
}

\author{
Sasui Sasui a,*, Watcharin Jinwuth ${ }^{\text {a }}$, Sirimas Hengrasmee ${ }^{a}$ \\ ${ }^{a}$ Department of Architecture; Faculty of Architecture; Naresuan University, Phitsanulok, 65000, Thailand
}

Manuscript Received May 23, 2018, Accepted July 17, 2018

\begin{abstract}
Adobe bricks are extensively used for the construction of adobe houses. The lack of strength is one drawback of these bricks; therefore the soil used to build these bricks is stabilized with several natural stabilizers. This study conducted to compare the effects of commonly used stabilizers, which are straw and rice husk on the compressive strength and tensile strength of adobe. Study provided the experimental data and the analyzed failure pattern of the stabilized and un-stabilized specimens subjected to unconfined compressive strength test and splitting test. From the obtained results, the increase in compressive strength, decrease in tensile strength, increase in the elasticity under compressive loads and no major failure under compression and tension was observed for the specimens containing stabilizers. Results revealed the maximum positive effects of straw than rice husk in improving the adobe's resistance to the compressive and tensile loads.
\end{abstract}

Keywords: Adobe brick; Strength; Stabilization; Straw; rice husk

\section{Introduction}

Adobe is a sun-dried mud brick which is used to construct adobe houses mainly in developing countries. Adobe houses are preferred due to the availability of soil and rapid construction [1-3]. The poor mechanical properties is a known drawback of adobe which can be improved with the stabilization method [4]. Stabilization by means of natural plant fibres is commonly practiced in the developing countries as they reduce the crack formation and increase the strength and durability of adobe [5]. Straw and rice husk are widely used stabilizer for earthen construction as they are available in abundance [6-8]. The effects of straw on the properties of adobe was 1st realized by Romans while the rice husk due to its pozzolanic properties is widely used in either raw or ash form to stabilize adobe soil as well as other masonry materials [7, 9-12].

The use of straw and rice husk as a stabilizer is because of the high production of rice crops in developing countries. The rice crop produces straw after harvesting and rice husk after milling [13-15]. Due to the common use of straw and rice husk, the studies investigated its effects particularly on the compressive strength, water absorption and thermal conductivity of adobe. Some studies found the negative effects particularly of straw stabilizer on the mechanical properties of adobe $[9,16]$. While some studies found the positive effects of these stabilizers on the mechanical properties of adobe $[8,17-19]$. The studies also reported the variation in results with the change in mixing ratio of stabilizer in soil $[17,19]$. However, it is difficult to compare the additive's

\footnotetext{
* Corresponding author. Tel.: +92 3423745880 .

E-mail address: sassuikhuwaja126@gmail.com (S.Sasui)
}

https://doi.org/10.29187/jscmt.2018.27 
effect by referring the results obtained in former studies as the stabilizers' reactivity depends on the soil type and its texture [20-22]. Therefore, the study investigated the effects of straw and rice husk on the same soil and in a same mixing ratio.

\section{Materials and Methods}

To carry on the research, the brief regarding material collection and testing methods is given in the following sub sections.

\subsection{Collection of material}

To prepare the specimens the soil was collected from the site located in Phitsanulok Province, Thailand. The soil collected from the site was clayey, in order to make the soil suitable for construction, the amount of sand was added to the soil. After adding the sand; the soil comprised of $48 \%$ sand and $52 \%$ fines which is suitable for the production of adobe brick [23].

The stabilizer straw was collected from rice field and chopped to the length of $40 \mathrm{~mm}$ as it is recommended by Boudreau (24), refer to figure 1 (A). While the raw rice husk was collected from local rice mill, which was slightly compacted to reduce its pointed ends, refer to figure 1 (B). These stabilizers were added to the soil by the weight of dry soil, the proportion of dry mixture is presented in table 1 . The water was added gradually to obtain the optimum plasticity and was kneaded manually for the proper consistency of mixture.

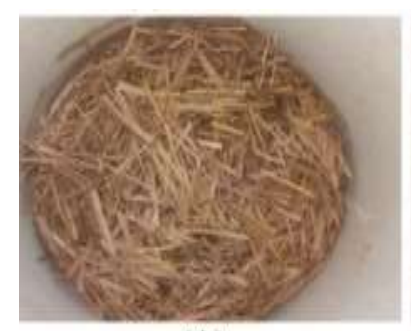

(A)

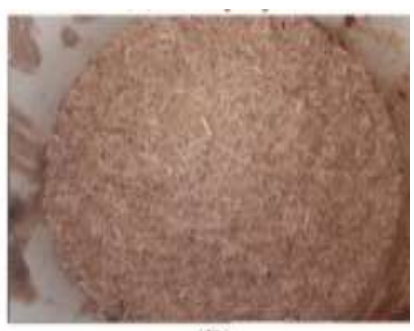

(B)

Fig. 1. Prepared stabilizers; (A) straw, (B) rice husk

Table 1. The ratio of dry mixture; (A) plain soil mixture; (B) straw stabilized soil mixture and (C) rice husk stabilized soil mixture.

\begin{tabular}{llll}
\hline Group & Mixture & Soil 'Wt. \%' & Stabilizers 'Wt. \%’ \\
\hline A & Soil only & 100 & 0 \\
B & Soil + Straw & 98 & 2 \\
C & Soil + rice husk & 98 & 2 \\
\hline
\end{tabular}

\subsection{Sample preparation}

For each experiment, the specimens were cast manually from three groups of mixtures, therefore A, B \& C. The wooden mould was used to cast 15 stacked prism units ( 5 from each mixture group) and the cylindrical metal mould was used to cast 15 cylinders ( 5 from each group). The moulded dimension; L x W x H of stacked prism units is $200 \times 150 \times 300+$ mortar thickness $(\mathrm{mm})$ and the moulded dimension of cylindrical specimen is $202 \mathrm{~mm}$ height $(\mathrm{H})$ and $95 \mathrm{~mm}$ diameter (D). The lubricant was applied inside the moulds while moulding the specimens. All the moulded specimens were cured for 28 days under the sheds at $29( \pm 5){ }^{\circ} \mathrm{C}$ average temperature and $69( \pm 5) \%$ average relative humidity. The mean average parameters of the stacked prism specimens and cylindrical specimens after 28 days of curing were measured as presented in table 2 , figure 2 showing the cured specimens of each group. 


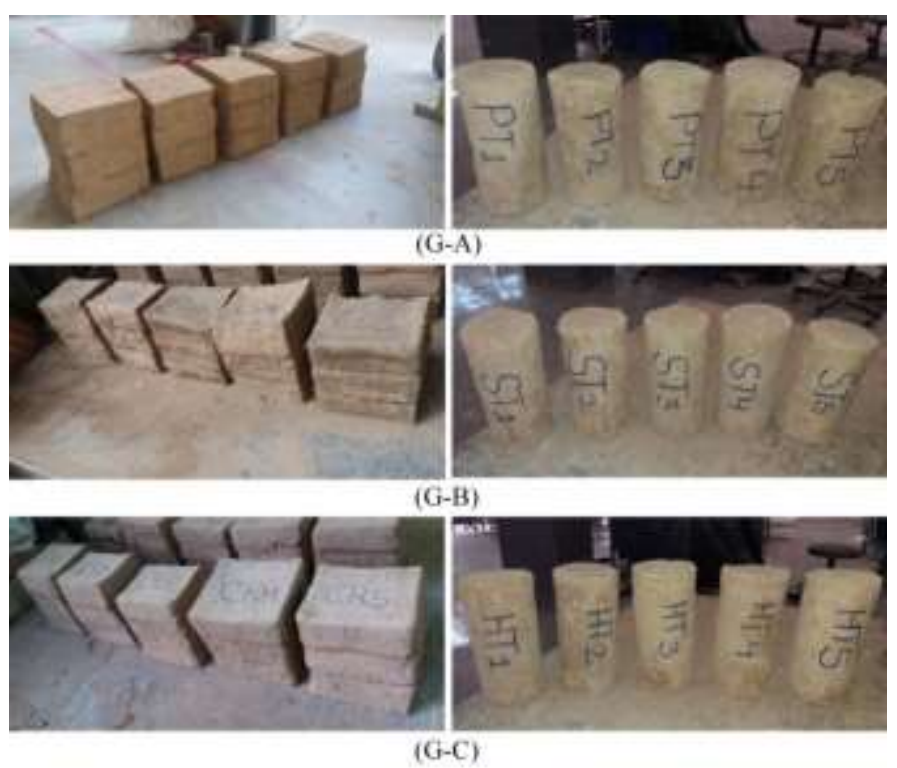

Fig. 2. Cured specimens from Group-A, Group-B \& Group-C

Table 2. The mean average parameters of stacked prism unit specimens (SPS) and cylindrical specimens (CS)

\begin{tabular}{|c|c|c|c|c|}
\hline Group & $\begin{array}{l}\text { (SPS) } \\
\text { L X W X H mm³ }\end{array}$ & $\begin{array}{l}\text { (SPS) } \\
\text { CV \% }\end{array}$ & $\begin{array}{l}\text { (CS) } \\
\mathrm{H} ; \mathrm{D} \mathrm{mm}\end{array}$ & $\begin{array}{l}\text { (CS) } \\
\text { CV \% }\end{array}$ \\
\hline A & $174 \times 127$ X 254.8 & 2.10 & $\mathrm{H}=181 \mathrm{D}=88.4$ & 1.97 \\
\hline B & $192.5 \times 133.5 \times 275.5$ & 1.18 & $\mathrm{H}=189.4 \mathrm{D}=90.2$ & 1.04 \\
\hline $\mathrm{C}$ & $188.2 \times 135.6 \times 279.2$ & 1.59 & $H=187 \mathrm{D}=90.02$ & 1.13 \\
\hline
\end{tabular}

\subsection{Unconfined compressive strength test methods}

Following the AS-3700 testing procedure as briefed in Australian earth building handbook [23]. The compressive strength test was carried out on all 15 stacked prism specimens. The specimens' height to width ratio $(\mathrm{H} / \mathrm{W})$ as presented in table 3 was complied with testing requirements and tested in compression testing machine model Tecnotest KL200 as illustrated in figure 3 (A). The load applied on the specimens was even at $0.5-1.0 \mathrm{Mpa} / \mathrm{min}$ rate. The maximum ultimate load ' $P$ ', specimen's cross-section area ' $A$ ' and correction factor ' $\mathrm{Ka}$ ' was computed in the equation 1 to calculate the unconfined compressive strength ' $\mathrm{C}$ ' in Mpa.

$$
C=K a \times P \div A
$$

\subsection{Splitting test method}

The Splitting test was conducted on 15 cylindrical specimens to determine the tensile strength. The specimens' parameters i.e. height to diameter ratio (H/D) as presented in table 3 were complied with the standard RILEM CPC 6 TC (25) which is designed for concrete specimens. To determine the tensile strength of adobe specimens by splitting method, the limit was applied to the loads and machine's travelling speed following the indication of Australian earth building hand book for compression test [23, 26, 27]. All the specimens were placed in a load control compression testing machine as illustrated in figure 3 (B). After the removal of loads, the ultimate load ' $P$ ' was recorded and computed in the equation 2 along with the specimen's height ' $H$ ' and diameter ' $D$ ' to calculate the tensile strength ' $T$ ' in Mpa.

$$
T=2 P \div \pi H D
$$


Table 3. Mean parameters of stacked prism specimens (SPS) and cylindrical specimens (CS)

\begin{tabular}{llllll}
\hline \multirow{2}{*}{ Group } & $(\mathrm{SPS})$ & $\begin{array}{c}(\mathrm{SPS}) \\
\text { H/W RatioKa }\end{array}$ & $\begin{array}{l}\text { (SPS) } \\
\text { Weight Kg }\end{array}$ & $\begin{array}{l}\text { (CS) } \\
\text { H/D Ratio }\end{array}$ & $\begin{array}{l}\text { (CS) } \\
\text { Weight Kg }\end{array}$ \\
\hline A & 2.01 & & 13.40 & 2.04 & 2.31 \\
B & 2.06 & & 12.21 & 2.09 & 2.23 \\
C & 2.06 & 0.70 & 12.24 & 2.07 & 2.38 \\
\hline
\end{tabular}

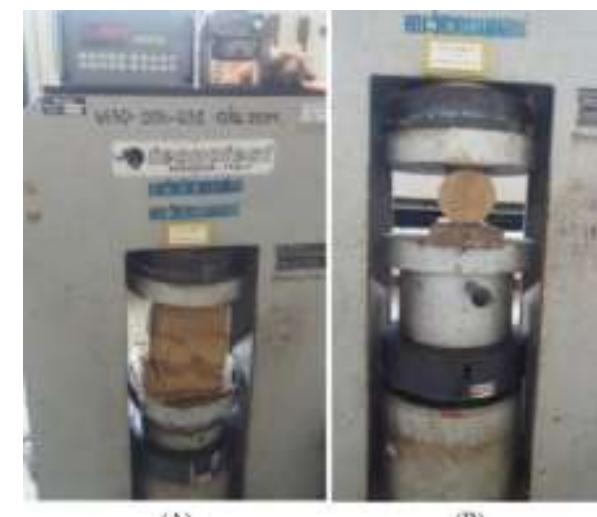

(A)

(B)

Fig. 3. Experimental set-up.

\section{Experimental Results}

Following the methods as briefed in section 2.3 and 2.4, the test was conducted on the cured specimens shown in figure 2. After conducting the proposed tests, the results obtained from each test is analysed as briefed in the sections below.

\subsection{Un-confined compressive strength test results}

The results obtained from compression test as illustrated in table 4, showing both stabilizers improved the unconfined compressive strength ' $\mathrm{C}$ ' and stress under compression ' $\sigma \mathrm{c}$ ' of adobe. However, the specimens containing rice husks improved more strength than the straw stabilized specimens. The results also showing the stabilized specimens obtained more failure strain ' $E$ ' ' and less modulus of elasticity 'Ec'. It indicates that the stabilized specimens are more elastic than the un-stabilized specimens. According to the results, the straw has retained more positive effects on the elasticity of adobe than rice husk.

Besides the factor of strength, the compressive strength determination of adobe also depends on its failure under loads $[5,28]$. Thus the study determined the effectiveness of fibers by analyzing the failure pattern of specimens under compressive loads. The specimens of group A deformed in a brittle mode with very few wide cracks as shown in figure 4 (A). While the specimens containing straws 'figure 4 (B)' exhibits the number of gentle cracks which doesn't lead to the detachment of the specimens and thus the specimen was not observed in failure. The rice husk stabilized specimens as shown in figure $4(\mathrm{C})$, on the other hand deformed in a ductile mode with minor exfoliation while the core of specimen remained coherent. From the failure of specimens at the ultimate compressive loads it is clear that resistance capacity of brick increased with the addition of straw and rice husk, but the straw renders more resistance to compressive loads than rice husk. 


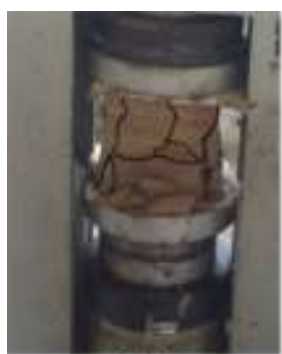

(A)

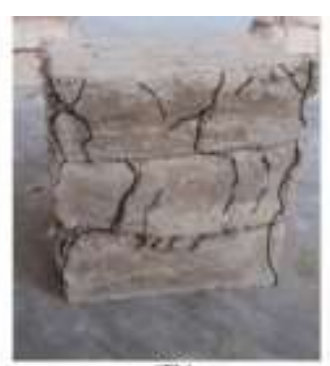

(B)

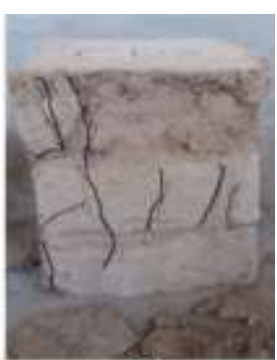

(C)

Fig. 4. Failure pattern under compressive loads

Table 4. Results of compression test and splitting test

\begin{tabular}{llllllllll}
\hline \multirow{2}{*}{ Group } & Avg. C & Avg. $\sigma c$ & CV & $\varepsilon c$ & CV & Ec & Avg. T & $\begin{array}{l}\text { Avg. } \sigma t \\
\text { CV }\end{array}$ & $\begin{array}{l}\text { CV } \\
\%\end{array}$ \\
& MPA & MPA & $\%$ & $\mathrm{~mm} / \mathrm{mm}$ & $\%$ & MPA & MPA & MPA & 7.50 \\
A & 1.36 & 1.94 & 2.91 & 0.03 & 6.31 & 64.66 & 0.28 & 0.44 & 7.27 \\
B & 1.49 & 2.21 & 0.87 & 0.091 & 7.74 & 24.29 & 0.25 & 0.393 & 7.27 \\
C & 1.69 & 2.42 & 2.86 & 0.056 & 6.98 & 43.21 & 0.23 & 0.361 & 7.52 \\
\hline
\end{tabular}

\subsection{Splitting test results}

The splitting test results presented in table 4 showing the decrease in tensile strength ' $T$ ' and tensile stress ' $\sigma \mathrm{t}$ ' with the addition of stabilizers. The effectiveness of these stabilizers is determined by the pattern of failure under tensile loads. At the ultimate load, the wide shear crack appeared on the un-stabilized specimens which thus marked the separation of a specimen as shown in figure 5 (A). While on the stabilized specimens, the columnar crack appeared as shown in figure 5 (B) \& (C). Although, the crack on specimens containing rice husk was broad but no major rupture was observed on the specimen as shown in figure $5(\mathrm{C})$. Whereas the crack on the specimen containing straw was fine and the specimens did not deform after the removal of load 'refer figure 5 (B)'. From the results it is attributed that the straw fibres are efficient in distributing the loads in material's matrix and thus prevent the specimens from brittle failure.

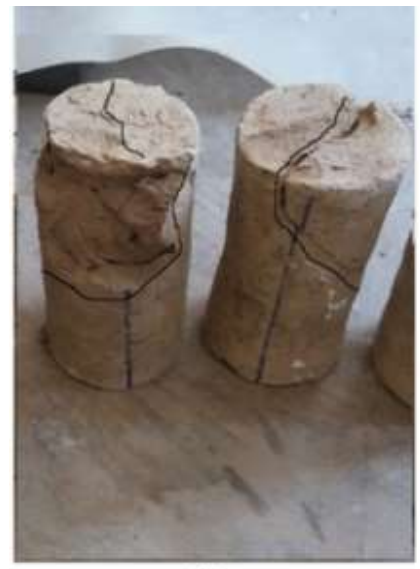

(A)

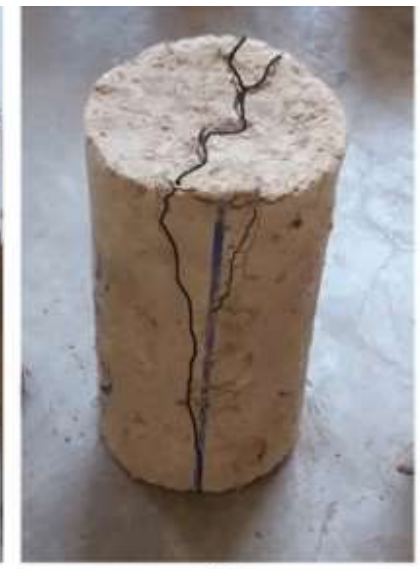

(B)

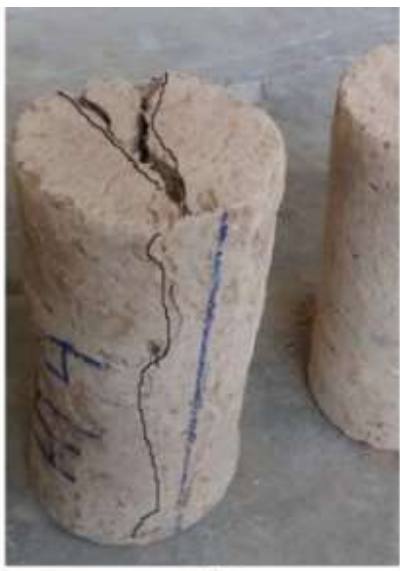

(C)

Fig. 5. Failure pattern under tensile loads

\section{Discussion}


A Result reveals the stabilizers i.e. straw and rice husk improved the elasticity \& ductility of specimen under the compressive \& tensile loads. This improvement is due to the flexibility and tensile property of stabilizer as well as the fiber-stabilizer bond. The material matrix of stabilized specimens under the loads worked as a structural-mesh which distributed the exerted loads throughout the soil matrix. In a result, the improvement in elasticity of materials and delay in the failure under the loads was observed. The positive effects of straw in mud could be due to its long fiber as it is assumed for the bagasse fiber [8]. While the positive effects of rice husk stabilizer is due to the presence of siliceous material, which retains cementing property [29].

On the comparison of bagasse fiber with rice husk in the past study, the bagasse showed maximum positive effects and the reason assumed is the long fibers of bagasse [8]. This could also be the reason behind the more efficient performance of straw than the rice husk under the loads. The long fiber provided the stronger bond in the straw-soil composition due to this the maximum improvement in elasticity and ductility was observed on the specimen containing straw.

Additionally, the results obtained in this study showing the coefficient of variation (CV) as high as $7.74 \%$, which is thus acceptable as the specimens were prepared manually [30].

\section{Conclusion}

To compare the effects of adobe specimens stabilized with straw and rice husk in the same ratio, the unconfined compressive strength test and the splitting test was carried out. Results showed the decreased tensile strength and increased compressive strength for the specimens containing straw and rice husk. These stabilized specimens showed the significant effects in increasing the failure strain and in decreasing the modulus of elasticity under compressive loads. This effect of stabilizers could be due to the tensile property of fibres which actively resist the external loads.

Although, the straw did not show the significant increase in compressive strength as the rice husk did. Straw also reduced the tensile strength of adobe, however, it increased the green strength of adobe more than the rice husk. The failure strain was also recorded higher for the specimens containing straw and no failure was observed on straw stabilized specimens at ultimate compressive and tensile loads. This observed effect of straw is due to its long fiber which holds the soil particles and results in the efficient transfer of induced loads throughout the bulk of the material. As a consequence, straw is an effective stabilizer than rice husk in improving the mechanical properties of adobe. Thus the study provides the guideline for the application of straw stabilized adobe brick for the construction of load-bearing walls.

\section{Acknowledgements}

We thank the staff of faculty of Architecture and faculty of Engineering, Naresuan University for their assistance in carrying out the research.

\section{References}

1. E.W. Smith and G.S. Austin, Adobe pressed-earth and rammed-earth industries in New Mexico, NMB. MM (1989).

2. E. Lynne and A. Cassandra, Alternative Construction: Contemporary Natural Building Methods, JW.A (2000).

3. G. Minke, Building with earth: design and technology of a sustainable architecture, Walter de Gruyter (2012).

4. E. Adam and A. Agib, Compressed stabilised earth block manufacture in Sudan, UNESCO (2001).

5. H. Houben and H. Guillaud, Earth construction A comprehensive Guide, 1st ed., ITDG (1994).

6. B. Sidibe, Understanding Adobe, VITA (1985).

7. P. Lertwattanaruk and J. Tungsirisakul, JARS, 5, (2007) 187.

8. P. Lertwattanaruk and J. Choksiriwanna, Built, 1 (2011) 54.

9. E. Quagliarini and S. Lenci, JCH, 11 (2010) 309.

10. R. Jauberthie, F. Rendell, S. Tamba and I. Cisse, Constr. Build. Matr, 14 (2000) 419.

11.P. Speare, K. Eleftheriou, S. Siludom, R. Dhir, T. Jappy and T. Telford, Durability of concrete containing rice husk ash as an additive, Int. Sem. Exp. W. Conc. (1999). 
12.H. Isah, The effect of rice husk on the chemical properties of clay soil, ICCBES (2015).

13.P. Monteiro and P. Mehta, Concrete: Structure, properties, and materials, Prentice-Hall (1993).

14.IRRI, Report of the Fifth External Programme and Management Review of International Rice Research Institute, FAO-UN (1998).

15.H. Molla, Study of stabilized mud brick as an alternative building material \& development of models, AAU. (2012).

16. Ş. Yetgin, Ö. Çavdar and A. Cavdar, Constr. Build. Matr, 22 (2008) 222.

17.J. Akinyele, O. Olateju and O. Oikelome, NIJOTECH, 34, (2015) 672.

18. G. Chaudhary, V. Kumar and M. Kumar, An experimental study on the capacity assessment of mud brick with impregnated straw, IIT. Gandhinagar (2016).

19.M. Bouhicha, F. Aouissi and S. Kenai, Cement. Concrete. Comp. 27 (2005) 617.

20.A.B. Ngowi, Constr. Build. Matr, 11, 1 (1997).

21.A. Kumar, B.S. Walia and J. Mohan, Constr. Build. Matr, 20, (2006) 1063.

22. N. Sriwattanaprayoon, Engineering Properties of Adobe Brick for Earth Structures, IJERD, 41 (2014).

23.P. Walker, The Australian earth building handbook, SAA (2002).

24.E.H. Boudreau, Making the adobe brick, Berkeley. CA. (1971).

25.R. TC, Recommendations for the Testing and Use of Constructions Materials, RILEM, E \& FN SPON, 21 (1994).

26.D. Silveira, H. Varum and A. Costa, Constr. Build. Matr, 28 (2011) 36.

27.D. Silveira, H. Varum and A. Costa, Constr. Build. Matr, 40 (2013) 719.

28.V.Z. Bosiljkov, Y.Z. Totoev and J.M. Nichols, SEM, 20 (2005) 21.

29. A. Muthadhi, Studies on production of reactive rice husk ash and performance of RHA concrete, Pondicherry Engineering College, (2010).

30.W. Jinwuth, A study into the earthquake resistance of circular adobe buildings, University Technology of Sydney, (2012). 